\title{
Anti-Fat Attitude in Society and Healthcare: The Need to Reduce a Big Issue
}

\author{
Kumar $\mathbf{M}^{1^{*}}$ and Saxena $\mathrm{I}^{2}$
}

${ }^{1}$ Department of Physiology, TS Misra Medical College Lucknow, India

${ }^{2}$ Department of Biochemistry, All India Institute of Medical Sciences Jodhpur, India

*Corresponding author: Manoj Kumar, Department of Physiology, TS Misra Medical College Lucknow, India; Tel: 09415011315; E-mail: Premmanoj2001@yahoo.co.in

Received date: December 20, 2017; Accepted date: December 21, 2017; Published date: December 26, 2017

Copyright: (C) 2017 Kumar M, et al. This is an open-access article distributed under the terms of the Creative Commons Attribution License, which permits unrestricted use, distribution, and reproduction in any medium, provided the original author and source are credited.

\begin{abstract}
The number of overweight or obese persons is increasing in every country, and will probably not decline in the near future. Overweight obese persons have to face discriminatory attitude in the society as well as in healthcare centers, which affects their psychology as well as health. Many obese as well as normal weight people are unaware that this fat-shaming is wrong and should be stopped. Some healthcare providers believe that fat-shaming their obese patients will motivate them to lose weight. However, the mental anguish produced by such fat-shaming may compel such people to eat more, thus aggravating the problem. There is an urgent need to make the society and healthcare workers realize the ill-effects of the anti-fat bias so that such people may be treated with the empathy and respect that is the right of all human beings.
\end{abstract}

Keywords: Anti-fat attitude; Discrimination; Healthcare; Obesity; Society

\section{Introduction}

The social fabric in all countries comprises of groups, some of which are more favoured than others in terms of power, prestige, and privileges, leading to discrimination against the weaker groups. No nation can claim to be absolutely free from discrimination, as there are always some individuals in the role of either the victim or the victimizer. Extreme discriminations were responsible for slavery and genocides, less harsh forms are fewer chances of employment, more work for same pay, and derogatory remarks. Milder forms pervade all societies and are more subtle to discern (avoiding eye-contact or staring). Victims may perceive a glass ceiling or a sticky floor in the attainment of their goals, feel their liberty and happiness compromised, and report anxiety, depression, eating disorders, loss of interest, or even feelings of guilt. This produces compromised performance, substance abuse, development of inferiority complex or of dislike for others, or a sense of alienation from the society resulting in self withdrawal.

Obesity is a stigma that can be openly discriminated against in all societies, without evoking sympathy for the victim. Anti-obesity attitude is present even in pre-school children [1]. The self-esteem measured in normal weight and overweight pre-school children was of similar levels but was found to decrease in overweight children on starting school $[2,3]$. A consequence of discrimination shown by peers, educators, and sometimes, even the parents [4,5]. Students with obesity have fewer chances of securing admission in colleges compared to normal weight persons with equal academic achievements, especially if also female. There are fewer chances of obtaining employment/ promotion at work places, and higher chances of termination for employees suffering from obesity as they are judged more harshly [6]. Insurance companies increase premium costs for persons with obesity but do not cover treatment costs for obesity. People who are fat are considered flawed and damaged by doctors and insurance companies, but are perceived as able-bodied masquerading as the disabled in courtrooms $[5,6]$. To be fat is to be tainted in everyday life, and throughout life [7].

Healthcare centres should be free from all forms of discrimination. Overt expression of prejudice has declined substantially in healthcare as socially aware healthcare workers are deliberately impartial in caring for patients. However, negatively biased attitudes may be present even in the consciously egalitarian healthcare workers [8]. UNAIDS (a United Nations program on human immune deficiency virus and acquired immune deficiency syndrome) and the World Health Organization's Global Health Workforce Alliance setup an agenda for the elimination of all forms discrimination in healthcare [9]. The first Zero Discrimination Day of UN was celebrated on 1st March, 2014, as an opportunity "to celebrate everyone's right to live a full life with dignity regardless of age, gender, sexuality, nationality, ethnicity, skin colour, height, weight, profession, education, and beliefs" [10].

Stepping into a healthcare centre is often an ordeal for the obese, as the unwelcome atmosphere manifests itself right from the infrastructure and facilities: narrow doors, chairs with arm-rests, weighing scales unable to record more than 300 pounds, and small stretchers, wheelchairs, hospital gowns, blood pressure cuffs, and CT and MRI scanners [11]. Consequently, obese patients avoid making health check-up appointments, cancel appointments, or delay in seeking medical aid for tolerable conditions [12].

\section{Myths Associated With Obesity}

\section{Overindulgence causes obesity}

Most healthcare workers (including physicians) consider obesity as an avoidable condition resulting from the patient's overindulgent behaviour.

Obesity can result from both endogenous and exogenous causes. Endogenous causes may be hormonal (e.g. hypothyroidism, polycystic 
ovarian syndrome, Cushing's syndrome, central hypothyroidism, hypothalamic disorders, hyperprolactinemia), genetic, epigenetic, or may be a result of mother's age, diet and weight gain during pregnancy [13-16]. Some genetic disorders associated with obesity are apparent from the childhood, and may be classified into monogenic nonsyndromic disorders (e.g. melanocortin 4 receptor deficiency, leptin deficiency, leptin receptor mutation, proopiomelanocortin deficiency, proprotein convertase 1 deficiency); syndromic obesity (e.g. PraderWilli, Alstrom, Bardet-Biedl syndromes, etc.); and common polygenic obesity. More than 35 obesity susceptibility genes have been identified that interact with obesogenic environment to produce obesity, and 253 quantitative trait loci (QTL) have been identified for different obesityrelated phenotypes [17].

Calorie intake and expenditure imbalance is the root cause of exogenous obesity. High calorie intake may be due to increased purchasing power, availability of calorie dense foods, relatively higher costs of fruits and vegetables, temptations to consumers in the form of advertising, and easy availability of ready-made food. Easy availability of transport, work-saving devices, sedentary forms of entertainment, decreased accessibility to open spaces, increased sedentary activities at the work places and unsafe environment contribute to decreased physical activity. All these are components of obesogenic environment, and have more influence on obesogenic personalities, i.e., those people who are readily swayed by such factors.

Other exogenous factors include sleep debt, exposure to endocrine disrupting chemicals (EDCs), certain drugs, depression, chronic stress, reward eating, possibility of obesity-causing infections and gut microbiota [18-24].

\section{Assumption of easy weight loss}

People who are of normal weight often assume weight loss to be an easy matter of exercising more and eating less; actually, losing weight and maintaining the weight loss is tough as calorie restriction leads to a dip in the basal metabolic rate. The body attempts to regain the lost weight by reducing energy expenditure. An initial loss of weight is followed by regain of the lost weight when the diet is interrupted (yoyo dieting) [25]. A patient's inability to lose weight despite medical advice is viewed as non-compliance/over indulgence; and caregivers may even feel that every ailment in obese patients is due to the extra weight. Physicians may resort to shorter counselling time, hesitate to physically examine the patient or perform surgical procedures [26]. This is also because more complications are associated with surgery in the obese. Since data regarding dosage is usually obtained from normal weight persons, patients who are overweight may also suffer during treatment. Negative attitudes encountered in healthcare centres intimidate the patient, further aggravating the situation.

\section{Obesity: A Risk Factor for Many Diseases}

Health care professionals know that obesity is a risk factor for many conditions, and anticipate a bundle of health problems the moment such a patient appears on the threshold. Health problems related to obesity can be broadly classified into physical (e.g. skin conditions, sleep apnoea, and osteoarthritis), psychological (obesity stigma perceived throughout the overweight period of life leading to decreased social interaction, depression or resentment, and sometimes, bullying tendencies), and metabolic (metabolic syndrome, type 2 diabetes mellitus, dyslipidemia, atherosclerosis, hypertension, certain cancers, and diseases of heart, kidney, and liver) $[27,28]$. These facts suggest that there are high chances of healthcare centre visits by the overweight or obese, and it would be inhumane to provide suboptimal care to these patients.

\section{Increasing global burden of obesity}

Obesity has been declared a disease by the American Medical Association, and Europe may follow [29,30]. From being virtually nonexistent about 10000 years ago, obesity prevalence has increased substantially in the past three decades and is expected to rise further [31,32]. Healthcare workers may feel helpless and inadequate if they lack training in dealing with obesity. The simplest approach is to 'do no harm', as recommended by Standard: Treating the obese patient with respect may be the greatest gift that a doctor can offer to an obese patient [33].

\section{Steps for removing anti-obesity prejudice}

Biased attitudes can occur with or without conscious awareness. Education tools provided by The Rudd Center for Food Policy and Obesity help recognize negative attitudes and are used by healthcare workers and students to assess their explicit and implicit bias [34]. Healthcare workers must realize that being fat does not imply subnormal intelligence or steel armour to protect the victim from negativity. The society and the healthcare workers need to appreciate that there is a sensitive soul with a longing for a normal, happy life lurking under the fat!

\section{Conclusion}

The obesity epidemic is here to stay for a long time and efforts need to be made by healthcare workers and governments of all developed as well as developing countries to empathise with such patients. Infrastructure and equipment of healthcare facilities should accommodate severe obesity, so that there is no need to send an obese patient to the zoo for an MRI scan. Healthcare professionals need to understand that the overweight or obese people do not like being that way, and that weight once gained is not easy to lose. Continuous medical education programs for health providers and appropriate counselling to medical and nursing students can reduce the anti-fat prejudice, so that a more empathetic generation of healthcare providers is conceived [35,36]. The empathetic attitude of the healthcare professionals may help such patients lose weight.

\section{Funding}

None

\section{Conflicts of Interest}

None

\section{References}

1. Musher-Eizenman DR, Holub SC, Miller AB, Goldstein SE, EdwardsLeeper L (2004) Body Size Stigmatization in Preschool Children: The role of control attributions. J Pediatric Psychol 29: 613-620.

2. Klesges RC, Haddock CK, Stein RJ, Klesges LM, Eck LH, et al. (1992) Relationship between psychosocial functioning and body fat in preschool children: A longitudinal investigation. J Consult Clin Psychol 60: 793-796.

3. Pierce JW, Wardle J (1997) Cause and effect beliefs and self-esteem of overweight children. J Child Psychol Psychiat 38: 645-650. 
4. Van Geel M, Vedder P, Tanilon J (2014) Are overweight and obese youths more often bullied by their peers? A meta-analysis on the relation between weight status and bullying. Int J Obes 38: 1263-1267.

5. Puhl RM, Brownell KD (2001) Bias, discrimination, and obesity. Obes Res 9: 788-805.

6. Puhl RM, Heuer CA (2009) The stigma of obesity: A review and update. Obesity 17: 941-964.

7. Allon N (1982) The stigma of overweight in everyday life. New York, NY: Van Nostrand Reinhold pp.130-174.

8. Wilson TD, Lindsey S, Schooler TY (2000) A model of dual attitudes. Psychol Rev 107: 101-126.

9. http://www.who.int/workforcealliance

10. www.unaids.org/en/resources/campaigns/2017_zerodiscriminationday

11. Buckley O, Ward E, Ryan A, Colin W, Snow A, et al. (2009) European obesity and the radiology department. What can we do to help? Euro Radiol 19: 298-309.

12. Amy NK, Aalborg A, Lyons P, Keranen L (2006) Barriers to routine gynecological cancer screening for white and African-American obese women. Int J Obes 30: 147-155.

13. Weaver JU (2008) Classical endocrine diseases causing obesity. Front Horm Res 36: 212-228.

14. Pereira-Lima JF, Leaes CG, Neto FMF, da Rosa Barbosa MV, da Silva ALM, et al. (2013) Hyperprolactinemia and body weight: Prevalence of obesity and overweight in patients with hyperprolactinemia. Res J Endocrinol Metab 1: 2.

15. Herrera BM, Keildson S, Lindgren CM (2011) Genetics and epigenetics of obesity. Maturitas 69: 41-49.

16. Blair NJ, Thompson JM, Black PN, Becroft DM, Clark PM, et al. (2007) Risk factors for obesity in 7-year-old European children: The Auckland Birth weight Collaborative Study. Arch Dis Child 92: 866-871.

17. Rankinen T, Zuberi A, Chagnon YC, Weisnagel SJ, Argyropoulos G, et al. (2006) The human obesity gene map: The 2005 update. Obesity 14: 529-644.

18. Beccuti G, Pannain S (2011) Sleep and obesity. Curr Opin Clin Nutr Metab Care 14: 402-412.

19. Elobeid MA, Allison DB (2008) Putative environmental-endocrine disruptors and obesity: A review. Curr Opin Endocrinol Diab Obes 15: 403-408.

20. Leslie WS, Hankey CR, Lean MEJ (2007) Weight gain as an adverse effect of some commonly prescribed drugs: A systematic review. QJM 100: 395-404.
21. Dallman MF (2010) Stress-induced obesity and the emotional nervous system. Trends Endocrinol Metab 21: 159-165.

22. Capuron L, Lasselin J, Castanon N (2017) Role of adiposity-driven inflammation in depressive morbidity. Neuropsychopharmacology 42 : $115-128$.

23. Atkinson RL (2007) Viruses as an etiology of obesity. Mayo Clin Proc 82: 1192-1198.

24. Everard A, Cani PD (2013) Diabetes, obesity and gut microbiota. Best Pract Res Clin Gastroenterol 27: 73-83.

25. Soeliman FA, Azadbakht L (2014) Weight loss maintenance: A review on dietary related strategies. J Res Med Sci 19: 268-275.

26. Puhl RM, Heuer CA (2010) Obesity stigma: Important considerations for public health. Am J Public Health 100: 1019-1028.

27. Yosipovitch G, DeVore A, Dawn A (2007) Obesity and the skin: Skin physiology and skin manifestations of obesity. J Am Acad Dermatol 56: 901-916

28. Pi-Sunyer X (2009) The medical risks of obesity. Postgrad Med 121: 21-33.

29. http://www.npr.org/documents/2013/jun/ama-resolution-obesity

30. Vallgarda S, Nielsen MEJ, Hansen AKK, Cathaoir KÓ, Hartlev M, et al. (2017) Should Europe follow the US and declare obesity a disease?: A discussion of the so-called utilitarian argument. Eur J Clin Nutr 71: 1263-1267.

31. Brown PJ, Krick SV (2001) Culture and ethnicity in the etiology of obesity: Diet, television and the illusion of personal choice. London pp. 111-157.

32. Friedrich MJ (2017) Global obesity epidemic worseninng. JAMA 318: 603.

33. Stunkard AJ (1993) Talking with patients. New York: Raven Press pp. 355-363.

34. http://www.uconnruddcenter.org/weight-bias-stigma

35. Phelan SM, Burgess DJ, Burke SE, Przedworski JM, Dovidio JF, et al. (2015) Beliefs about the causes of obesity in a national sample of 4th year medical students. Patient Educ Couns 98: 1446-1449.

36. Poon MY, Tarrant M (2009) Obesity: Attitudes of undergraduate student nurses and registered nurses. J Clin N 18: 2355-2365. 